\title{
A Practical Approach for Demonstrating Environmental Sustainability and Stewardship through a Net Ecosystem Service Analysis
}

\section{Joseph Nicolette $^{1, *}$, Stephanie Burr ${ }^{2}$ and Mark Rockel ${ }^{3}$}

1 ENVIRON International Corporation, 1600 Parkwood Circle, Suite 310, Atlanta, GA 30339 USA

2 ENVIRON International Corporation, 333 West Wacker Drive, Suite 2700, Chicago, IL 60606 USA; E-mail: sburr@environcorp.com

3 ENVIRON International Corporation, 1760 Market Street, Suite 1000, Philadelphia, Pennsylvania 19103 USA; E-mail: mrockel@environcorp.com

* Author to whom correspondence should be addressed; E-Mail: jnicolette@environcorp.com; Tel.: 1-678-388-1665.

Received: 6 March 2013; in revised form: 26 April 2013 / Accepted: 27 April 2013 /

Published: 10 May 2013

\begin{abstract}
The increasing pressure on the earth's resources due to population growth requires that development and resource use be managed to maintain a sustainable environment so as to preserve or enhance human well-being. A practical approach for demonstrating the environmental sustainability of an action (e.g., green business practice) through ecosystem service analysis is presented. The overarching premise of the approach is that human well-being is directly related to changes in ecosystems and associated services. The approach evaluates the net change in ecosystem services, and hence human well-being, and is termed a net ecosystem service analysis (NESA). Using this approach, if a net positive change in ecosystem services relative to the baseline condition occurs for an action, that action would be considered potentially sustainable. In addition, if an action creates net ecosystem service value above the baseline condition, it would be considered to embody environmental stewardship. Established ecological and human use quantification methods are incorporated into the analysis. In addition, to demonstrate potential sustainability, the approach must also consider the need to satisfy intergenerational equity objectives. The use of a practical approach from which private business and government representatives can make decisions regarding environmental sustainability and stewardship will provide for improved decision-making based on quantifiable metrics.
\end{abstract}


Keywords: environmental sustainability; environmental stewardship; ecosystem services; net ecosystem service analysis; NESA; habitat equivalency analysis; HEA; net environmental benefit analysis; NEBA

\section{Introduction}

The concept of managing human population growth and development in a sustainable manner has become an emphasis of nations across the world [1]. In order to survive and flourish, people need to use the earth's resources; however, these resources are becoming increasingly scarce. The scarcity is exemplified not only through the loss of non-renewable resources such as minerals and fossil fuels, but also a diminishment in the quality of renewable resources (e.g., drinking water). The focus of sustainability is therefore directed at managing development and resource use [2]. As defined by the United Nations, sustainable development is development that meets the needs of the present without compromising the ability of future generations to meet their own needs [2]. Inherent in this definition is the incorporation of not only environmental issues associated with development but also economic and social issues. The consideration of environmental, social, and economic components in comprising sustainability is referred to as the "three pillars" of sustainability [3]. These "three pillars" are interdependent and effects to one will likely affect another. As such, sustainable development requires an understanding of the potential inter- and intra- tradeoffs among environmental, social, and economic components so as to maximize human well-being.

A practical approach for demonstrating the environmental sustainability of an action (e.g., green business practice) is critical to (1) determining the extent to which the practice provides a sustainable outcome at a meaningful scale, and (2) demonstrating environmental stewardship. A green business practice is defined herein as an action that is directly or indirectly aimed at improving the net environmental benefit associated with a project including consideration of the life cycle of its product. Hence, the purpose of implementing a green practice is to improve the overall flow of ecosystem service benefits. Approaches and metrics that can be used to measure sustainability and ecosystem services are evolving; however, there are some ecosystem service valuation methods that can be adapted to quantify the environmental performance of green business practices. These methods provide a technical and defendable basis to determine if actions proposed or implemented, promote environmental sustainability and stewardship. This paper presents a practical approach for demonstrating environmental sustainability and stewardship that incorporates the valuation of ecosystem services to help balance environmental, social, and economic issues with an endpoint to maximize human well-being.

\section{Sustainability and Ecosystem Services}

The United Nations definition of sustainability referenced above implies several levels of economic development. An economy with its population consuming at a subsistence level meets the definition but is probably not very desirable as a policy outcome. The economic literature has focused on two important concepts of sustainability: dynamic efficiency and intergenerational equity. The concept of 
dynamic efficiency is for society to choose that level of the mix of market goods and services and nonmarket goods and services that maximizes human well-being over time. This alone however does not mean it is sustainable as sustainability argues for intergenerational equity. The concept of intergenerational equity states that the total social welfare function must not decrease over time [4]. That is, the level of the mix of market goods and services and nonmarket goods and services that maximize human well-being over time must also not impede future generations from having at least the same level of human well-being. Stavins et al. [5] argue that not all actions or policies that pass the dynamic efficiency test are sustainable but that all sustainable actions or policies must be dynamically efficient; however, other economists, including Arrow et al. [4], argue that sustainability requires ensuring intergenerational equity. A potential criteria for intergenerational equity suggested in Stavins et al. [5] is to, at least in principle, have an action or policy that potentially has the ability to provide intergenerational transfers [5-7]. In summary, the goal of sustainability requires that an action or policy attempts to maximize the positive differences between benefits and costs (dynamic efficiency) and achieve intergenerational equity. For our purposes here we adopt the definition of sustainability which embodies both dynamic efficiency and intergenerational equity as developed by Stavins et al. [5].

The concept of dynamic efficiency is consistent with the Kaldor-Hicks criterion [8,9] which states that the world is viewed as being made better off from an action or policy if the total gains and the total losses are such that the gainers can fully compensate the losers for their losses and still be better off themselves. This notion of potential compensation is the underlying rationale for cost-benefit analysis (CBA). A CBA is a systematic process for quantifying and comparing the benefits and costs between competing alternatives such as a project, policy, or decision. Within a CBA, costs and benefits are typically expressed in terms of monetary units (e.g., dollars). In addition, CBA considers the net present value of cost and benefit flows over time. CBA has been incorporated across the world within a variety of policies (e.g., the United States, European Union, Canada, Austria, etc.). These have included policies related to infrastructure development (transportation such as roads, waterways, etc.) [10,11], mental illness [12], substance abuse [13], college education [14], and waste management [15] to name a few. In order for an action or policy to be considered sustainable, it needs to pass the CBA or Kaldor-Hicks criterion.

\section{Ecosystem Services}

The natural resources provided by the earth's ecosystems serve as the building block upon which human well-being flows. Ecosystems represent a complex and dynamic array of animal, plant, and microbe along non-living physical elements interacting as a functioning unit [16]. This gives rise to many benefits, known as ecosystem services, which are the benefits people obtain from naturally functioning ecosystems. Ecosystem services include provisioning services (e.g., food and water); regulating services (e.g., regulation of floods, drought); supporting services (e.g., soil formation and nutrient cycling); and cultural services (e.g., recreational, spiritual, religious and other nonmaterial benefits) [16]. The inter-relationship between ecosystem services and human well-being is complex [16]. 


\section{A Practical Approach to Demonstrate Sustainability}

A practical approach to demonstrate sustainability should be efficient in terms of both time and cost. These are both directly related to the level of effort and data requirements of the analysis. In addition, the approach should be science-based, technically defendable, and provide sufficient information for decision-making purposes. For decision-making, it is not necessary to quantify the entire suite of ecosystem services, it is only necessary to understand (1) those services that will change, given an action and (2) the level to which those services will change in comparison to the baseline condition. The net change (positive or negative) can be used to determine the overall environmental sustainability and stewardship of a proposed action compared to the baseline condition, the condition had the action not been implemented.

The approach presented herein incorporates the concept of a net ecosystem service analysis (NESA) to evaluate competing actions and their effects on human well-being. The overarching premise of the approach is that human well-being is directly related to changes in ecosystems and associated services. That is, when there is an action that affects, either positively or negatively, the flow of benefits provided by an ecosystem over time, there will be a resultant change or adjustment to human well-being. This resultant change represents a net change from the pre-action condition. The pre-action condition is also known as the baseline condition, the condition "but for" the action. The baseline condition of human well-being that is a result of the services provided by the ecosystem is represented in Figure 1. The resultant change in human well-being, the positive or negative consequential condition that occurs from an action that affects ecosystem services, is represented in Figure 2. The ecosystem service flows over time for the baseline and consequential conditions are conceptually depicted, for demonstrative purposes, in Figures 3-6. A gain in human well-being compared to the baseline condition is depicted in Figure 4 while a loss of human well-being is depicted in Figure 5. In some cases, an action may result in both positive and negative impacts on human well-being over time (Figure 6). It is important to note that the baseline level of services provided by a site or area is not constant and can vary over time based on a wide variety of factors that include seasonal changes in ecosystem habitats and species, ongoing habitat stressors such as pollution, population changes, and many other non-action related factors. This is consistent with the thought that human well-being is not a constant state but a constantly changing state. What matters is the "net" change (shaded areas in Figures 4-6) in human well-being that is associated with an action. Therefore, the focus should be on measuring the net change in ecosystem services compared to the baseline condition, not the entire suite of ecosystem services. If a net positive change in ecosystem services relative to the baseline condition occurs for an action, that action would be considered potentially sustainable. That is, the area above the curve should be greater than the area below the curve, given accounting for time changes in value (e.g., discounting).

An analysis of the net change in ecosystem services, and hence human well-being, is what is termed a NESA. A NESA is similar to a cost-benefit analysis (CBA) in that it is a systematic process for quantifying and comparing the benefits and costs between competing alternatives. However, a NESA does not necessarily rely on monetization but can include non-monetary environmental metrics. A NESA and a CBA are similar in that they consider time accumulated service flows (i.e., benefits and costs over time). Since these benefits and costs occur over varying time frames, they can be 
normalized to their net present value using a discount rate. The merits of a NESA type approach for evaluating site remediation, compensatory restoration, and ecosystem service tradeoffs have been discussed [17-20]. The incorporation of ecosystem service valuation into decision-making has also been referred to as a net environmental benefit analysis (NEBA) [17].

Figure 1. Representation of the baseline condition.

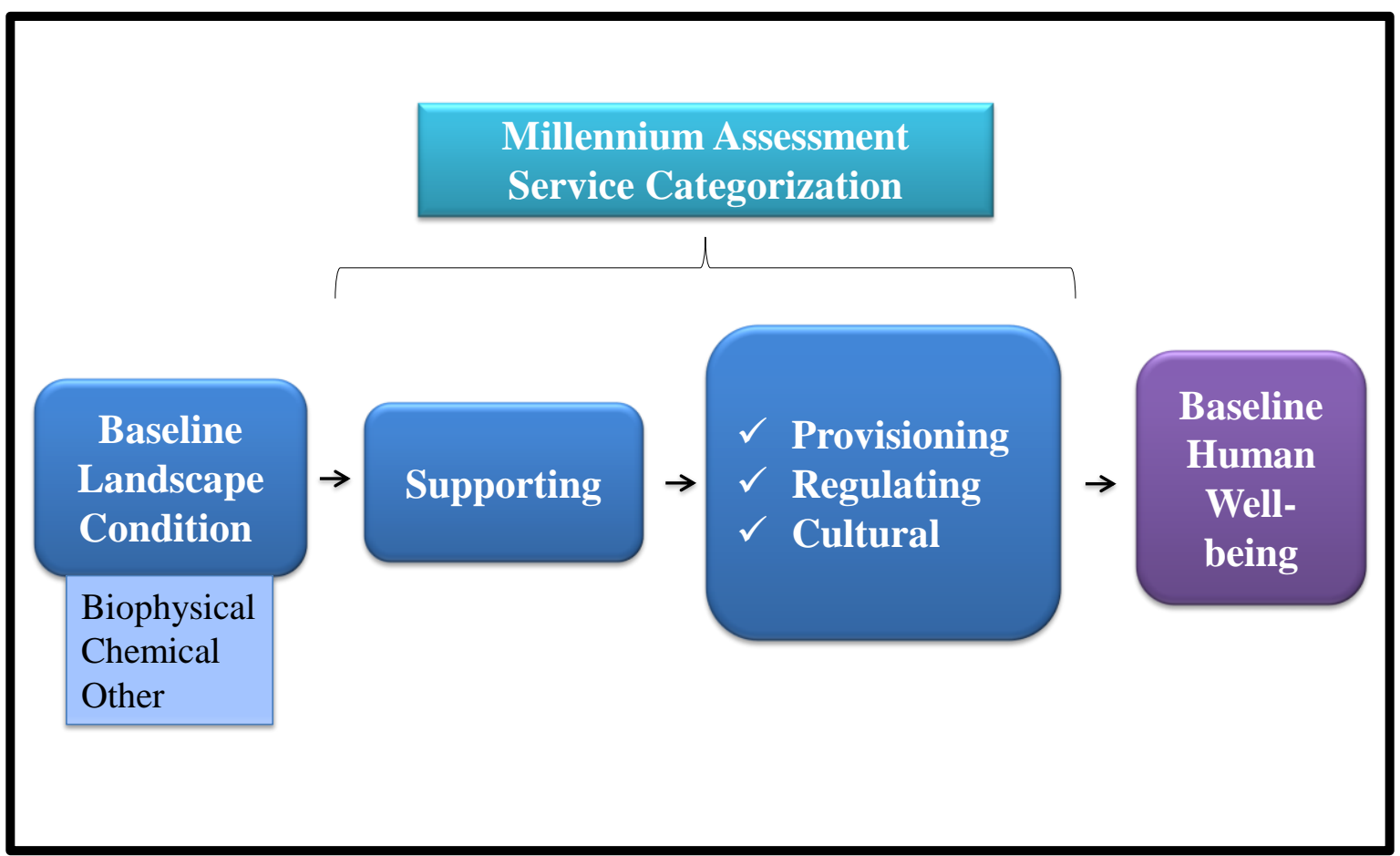

Figure 2. Resultant changes in human well-being that occur with project implementation.

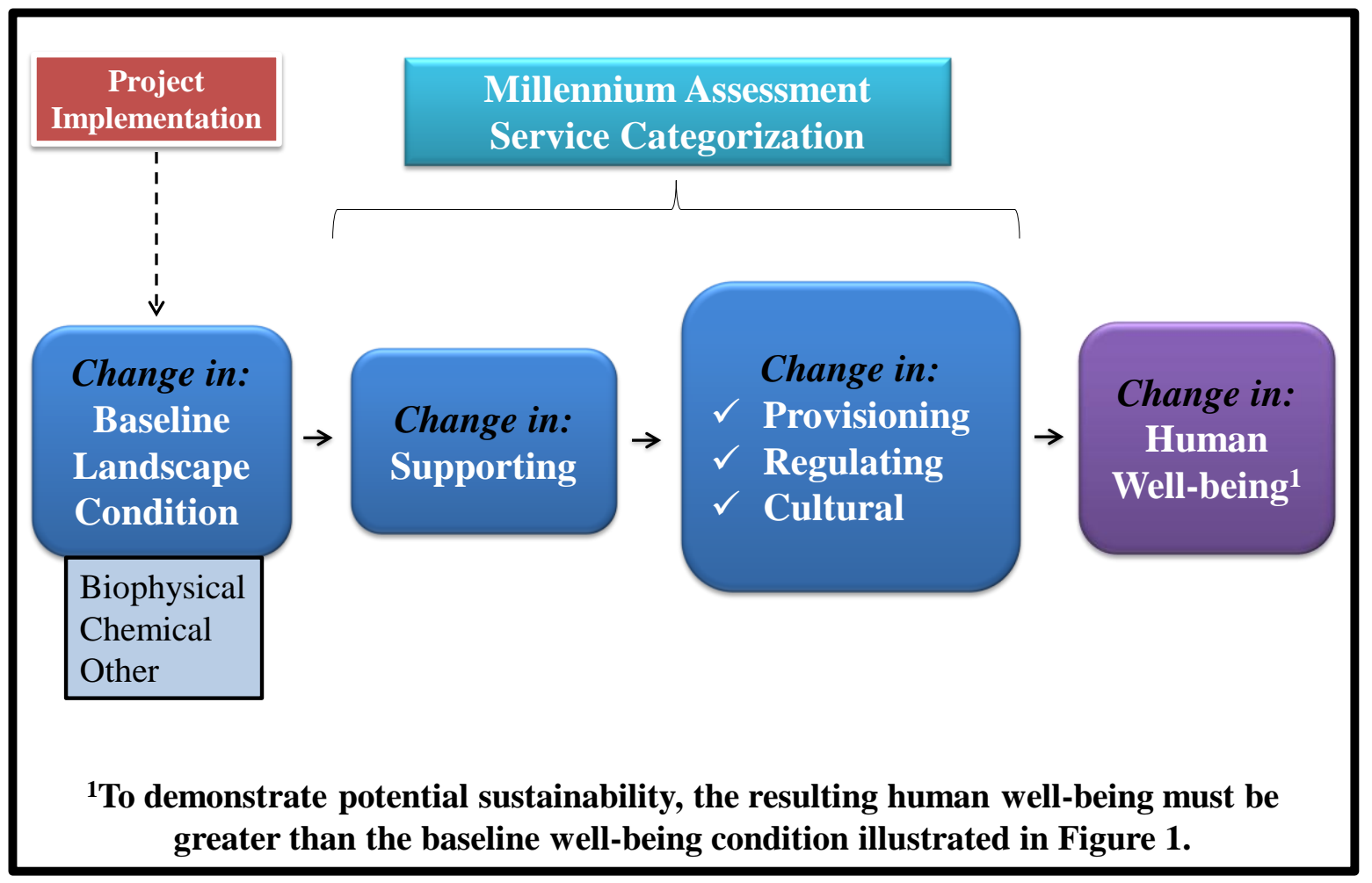


Figure 3. Representation of baseline ecosystem service flows.

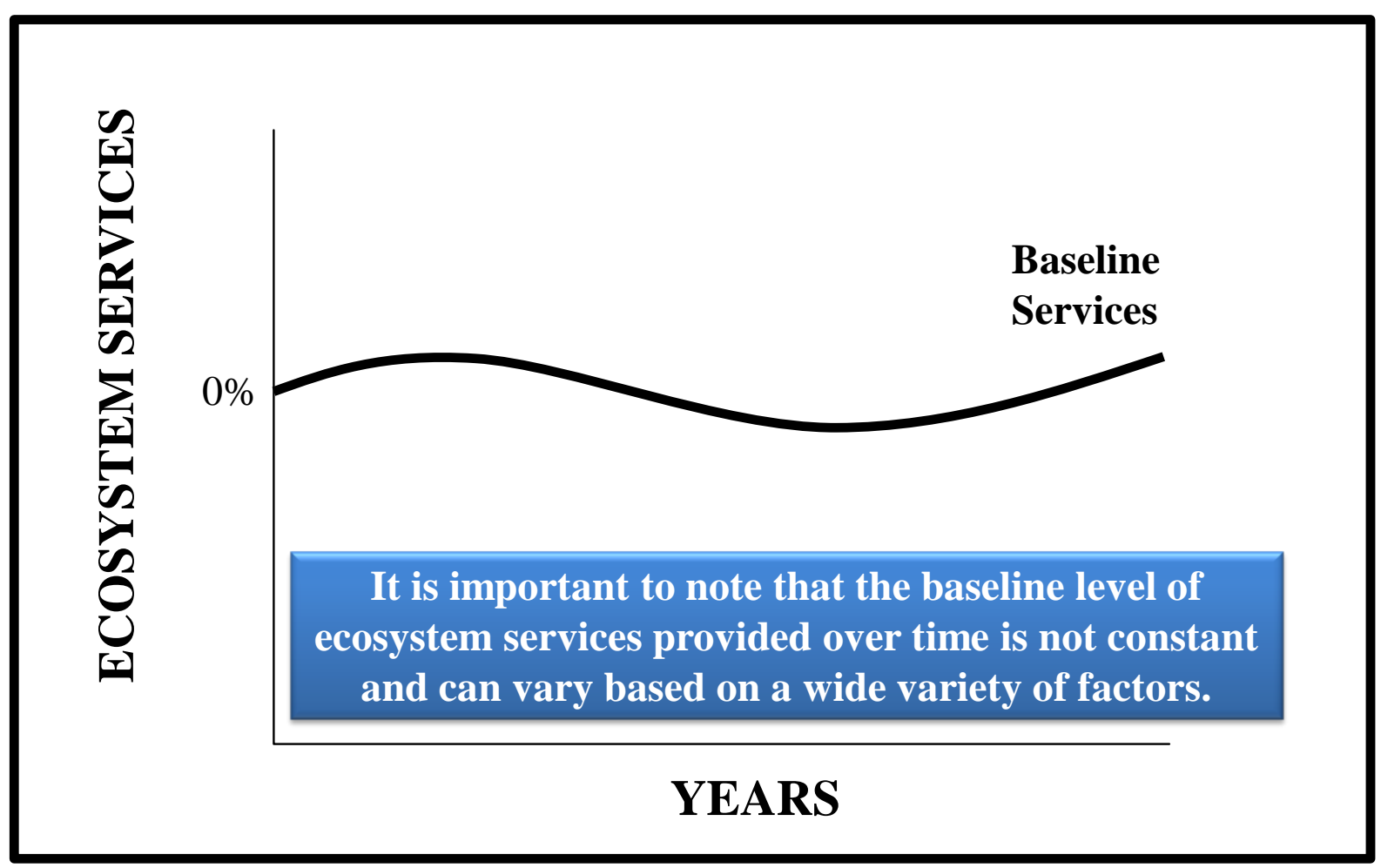

Figure 4. An action increases ecosystem services above the baseline condition (shaded area above baseline).

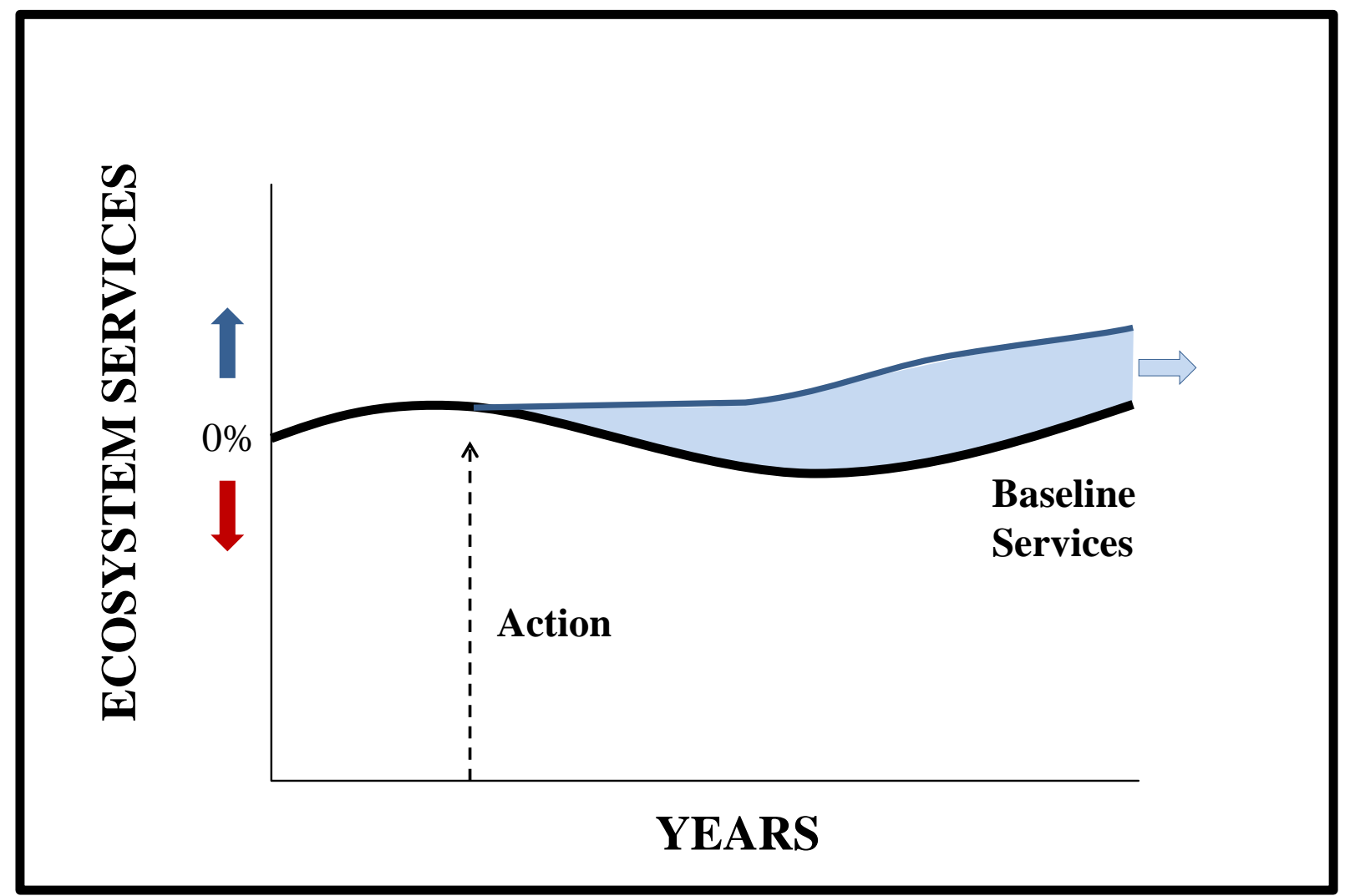


Figure 5. An action decreases ecosystem services below the baseline condition (shaded area below the baseline).

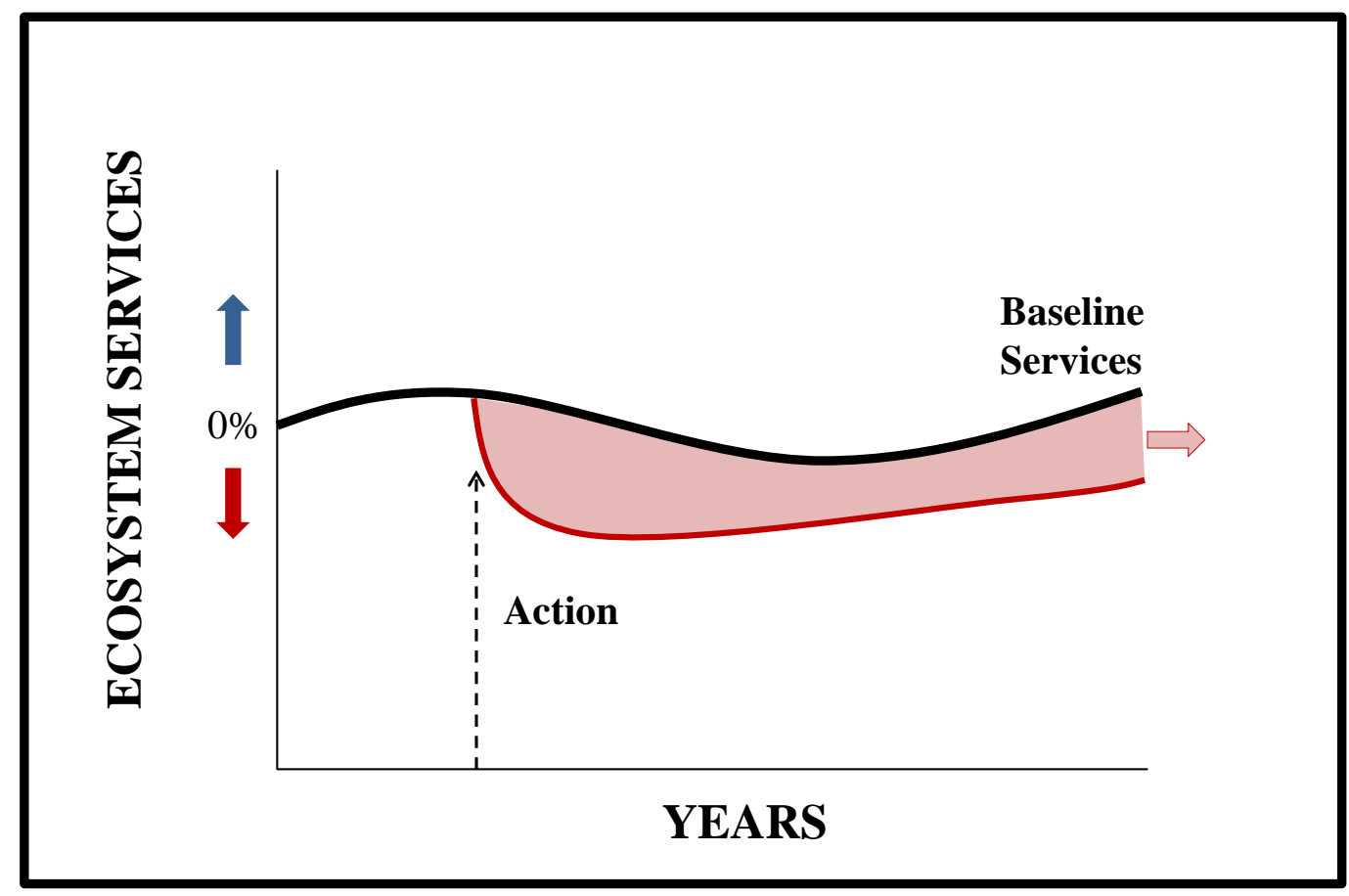

Figure 6. An action may increase and decrease ecosystem services over time compared to the baseline condition (shaded areas above and below baseline).

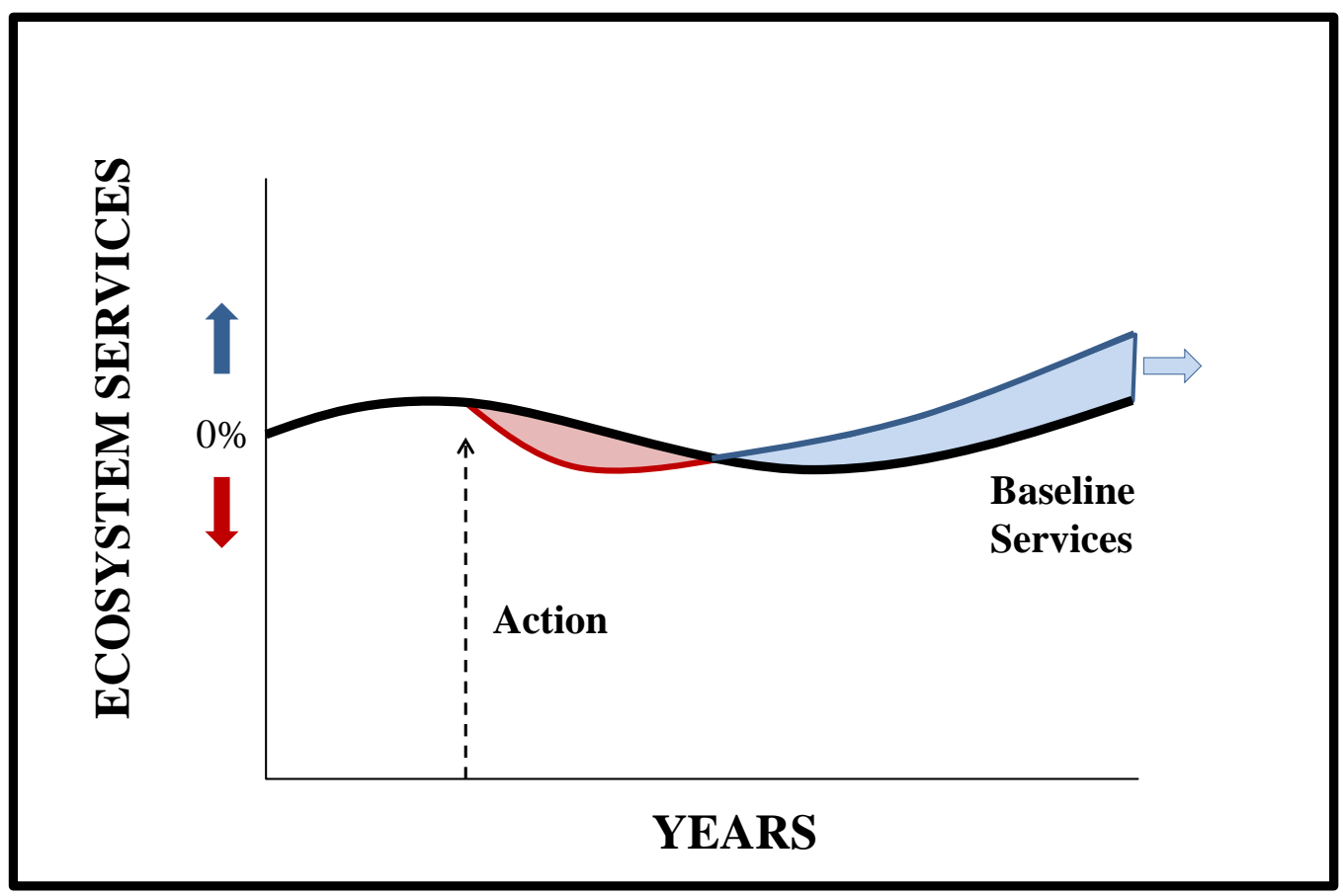

\subsection{Net Ecosystem Service Analysis}

NESA is a practical approach that utilizes U.S. agency-approved and litigation-tested techniques and tools for quantifying the ecosystem service losses or gains associated with actions that affect the 
environment. These techniques and tools have also been incorporated into guidance developed in the European Union associated with the Environmental Liabilities Directive [21]. A key point with NESA is that it is only necessary to evaluate the net change in ecosystem services associated with an action. Therefore, (1) it is not necessary, when comparing between alternative actions, to quantify the overall "stock" value of a resource and (2) the net change in ecosystem services can be represented using one or a combination of monetary and/or non-monetary metrics. In addition, the NESA approach is flexible regarding data needs. The overall approach may or may not be data intensive depending upon what assumptions can be made regarding parameter values. For example, in some cases, stakeholders have agreed on parameter values in a couple of days, in other cases, stakeholders have collected data over a several year period to support the analysis. All-in-all, the amount of data required will be based on the level of information needed to distinguish between the alternatives being evaluated and will be influenced by the decision being made, the level of certainty required, and the alternatives being compared.

\subsubsection{Ecosystem Service Quantification Approaches within NESA}

In order to evaluate how an action affects human well-being, quantification of changes, negative or positive, in ecosystem services is necessary. Our experience has shown that quantified estimates of ecosystem services sufficient for environmental decision-making can be obtained through the use of the valuation approaches developed and refined under the United States natural resource damage assessment (NRDA) process. Within NRDA, these approaches are used to balance compensatory restoration with adverse impacts so as to maintain the flow of natural resource services provided to the public. The approaches include economic-based methods to quantify the gains or losses in ecological and human use services associated with an action that affects the environment. It is within this context that the use of these economic-based methods is considered and takes advantage of the experience gained within the NRDA process over the past 20 years. We propose the use of these ecological and human use quantification methods to evaluate changes in ecological and human use services associated with green practices. In this manner, green practices can be compared regarding their ability to provide a net ecosystem service benefit and hence, their potential sustainability. The proposed approach does not necessitate that a restoration-based offset be incorporated into an alternative practice in order to demonstrate sustainability. The need and appropriateness of an offset should be discussed among the stakeholders involved.

In general, the term "natural resource services" as used within the NRDA process, is equivalent to the term "ecosystem services". Natural resource services are classified as either: (1) ecological services or (2) human use services [22-24]. Human use services are further grouped into direct (e.g., consumptive) and indirect (e.g., passive or non-consumptive) uses (Figure 7). It should be recognized that natural resources and associated habitats serve as the foundation from which human use services flow. The classification of ecosystem services used within the NRDA process and presented in Figure 7 helps to minimize the potential for double counting of ecosystem service flows that is apparent with the Millennium Assessment (MA) classification of ecosystem services [16]. In the MA classification [16], ecosystem services are segregated into supporting services from which regulating, provisioning, and cultural services flow (Figure 1). If service flows are quantified and valued according to this classification, there is a potential for considerable double counting of service values. For example, 
supporting services are those services, such as primary production, that support the production of provisioning, regulating, and cultural services. When both supportive and provisioning services, for example, are accounted for in the same analysis, the supporting services are counted twice, both directly and then indirectly through the production of provisioning services [25]. Double counting can also occur across provisioning, regulating, and cultural services as all categories are valued directly on their own and indirectly through their production and support of final ecosystem goods and services [25]. Unless ecological production functions for services are known and well specified, it is difficult to appropriately categorize, quantify, and value all service flows. Therefore, due to double-counting issues associated with quantifying ecosystem services within the MA classification, ecosystem service flows are quantified within the NESA approach according to the service classifications presented in Figure 7.

Figure 7. Classification of ecosystem services within the natural resource damage assessment (NRDA) process [24].

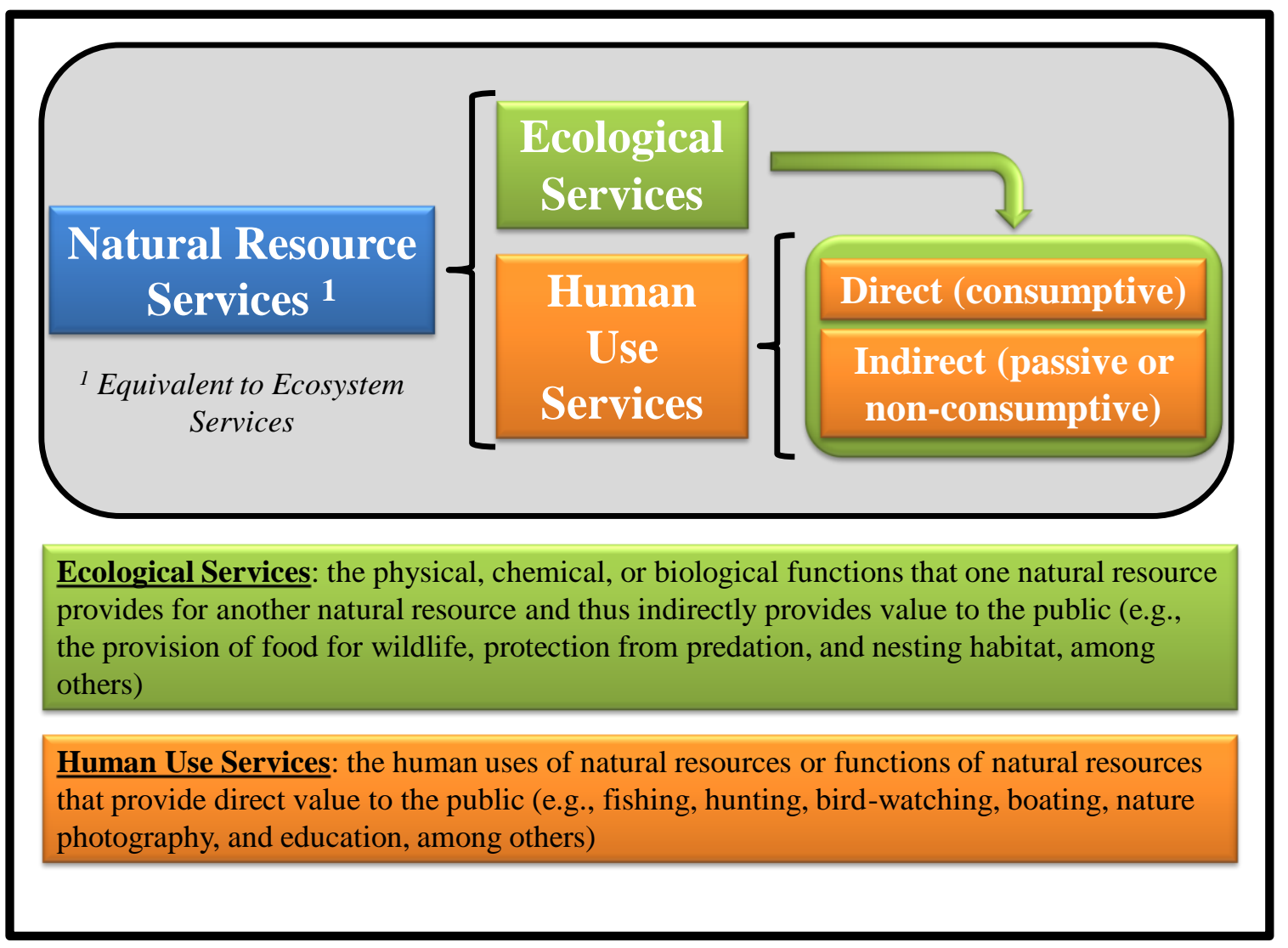

Within the United States, the need for compensatory restoration has resulted in the growth of the service-to-service approach to develop appropriately scaled compensation for contaminant releases [26-30]. The concept of the service-to-service approach is that compensation for lost ecosystem services can be conducted through the provision of services into the future. This concept inherently incorporates tradeoffs to make the public "whole". The tradeoff being the ability to provide equivalent habitat and/or human use services through restoration (i.e., offset project) to compensate for those services lost. The provision of ecological services can be conducted through restoration activities such as the acquisition, creation, enhancement or preservation of habitat. If required and determined to be appropriate, it is preferred that the restoration (i.e., the provision of habitat and human use services) 
be "in-kind", that is, replace the same type and quality of habitat impacted. In addition, it is preferred that the restoration be spatially connected (e.g., in the same watershed) to the impacted habitat. However, in several cases, compensatory restoration has been "out of kind" and not spatially linked to the watershed impact [30,31]. In these cases, the regulatory agencies preferred one habitat type over another or made a linkage between the restored resource and the injured resource (e.g., if a release impacted migratory waterfowl, habitat restoration that supports that species along its flyway has been accepted). These decisions were the basis of tradeoffs made on behalf of the public by the resource agencies involved. In regards to human use services, compensatory restoration has included projects that create human use value such as the creation of boat ramps, parks, etc.

It should be recognized that the incorporation of offsets is not always appropriate in the demonstration of environmental sustainability since ecosystem services are spatially explicit and it may not be possible to replace ecosystem services in some areas. In some cases, given the geographical location, certain ecosystem services may have a higher priority when compared to others, based upon their overall contribution to human well-being in that particular area. That is, the importance and priority associated with a specific ecosystem service can be different based upon the specific location to which that benefit is provided.

Sustainability requires that there be a sufficient stock of ecosystem assets to provide a continuum of ecosystem services into the future. If the stock of ecosystem assets falls below some critical threshold level, there is a potential that the associated ecosystem service flows would be reduced over time, become scarce and would have a higher future value to society [32]. Knowing which ecosystem assets are near, above or below a critical threshold is sometimes difficult to ascertain. Those ecosystem assets and the services they provide which have limited substitution possibilities could be candidates. In addition, the feasibility and costs associated with potential offset projects may be an indicator as to whether the ecosystem asset is potentially near a critical threshold. The appropriateness of incorporating an offset as part of the demonstration of the sustainability of a particular project is a case-by-case policy decision that should be discussed between the stakeholders.

The practical approach presented herein incorporates the ecological and human use quantification methods commonly used in the service-to-service approaches as a means to quantify changes in ecosystem service flows given an action that affects the environment. In addition, the impact and benefit metrics used within the methods consider both non-monetary and monetary ecosystem service flow metrics. These metrics can be incorporated into the evaluation of ecosystem service flows associated with green practices in order to establish their overall sustainability compared to a baseline condition. In some cases, the financial benefits may drive the development of a particular project and offsets may need to be developed if appropriate. As such, consistent with the definition of sustainability, offsets have the potential to be incorporated into the alternatives analysis of green practices and the quantification of net ecosystem service flows for the purposes of demonstrating sustainability. As stated above, offsets should be considered on a case-by-case basis.

In the following sections, we discuss the ecological and human use service quantification methods used within the service-to-service approach and their application within NESA to estimate the net change in ecosystem services associated with an action and present metrics for determining sustainability. The net change in ecosystem service value is depicted as the shaded areas in Figures 4-6. The practical approach presented herein is shown in Figure 8. 
Figure 8. Demonstrating Potential Environmental Sustainability using a Net Ecosystem Service Analysis Approach.

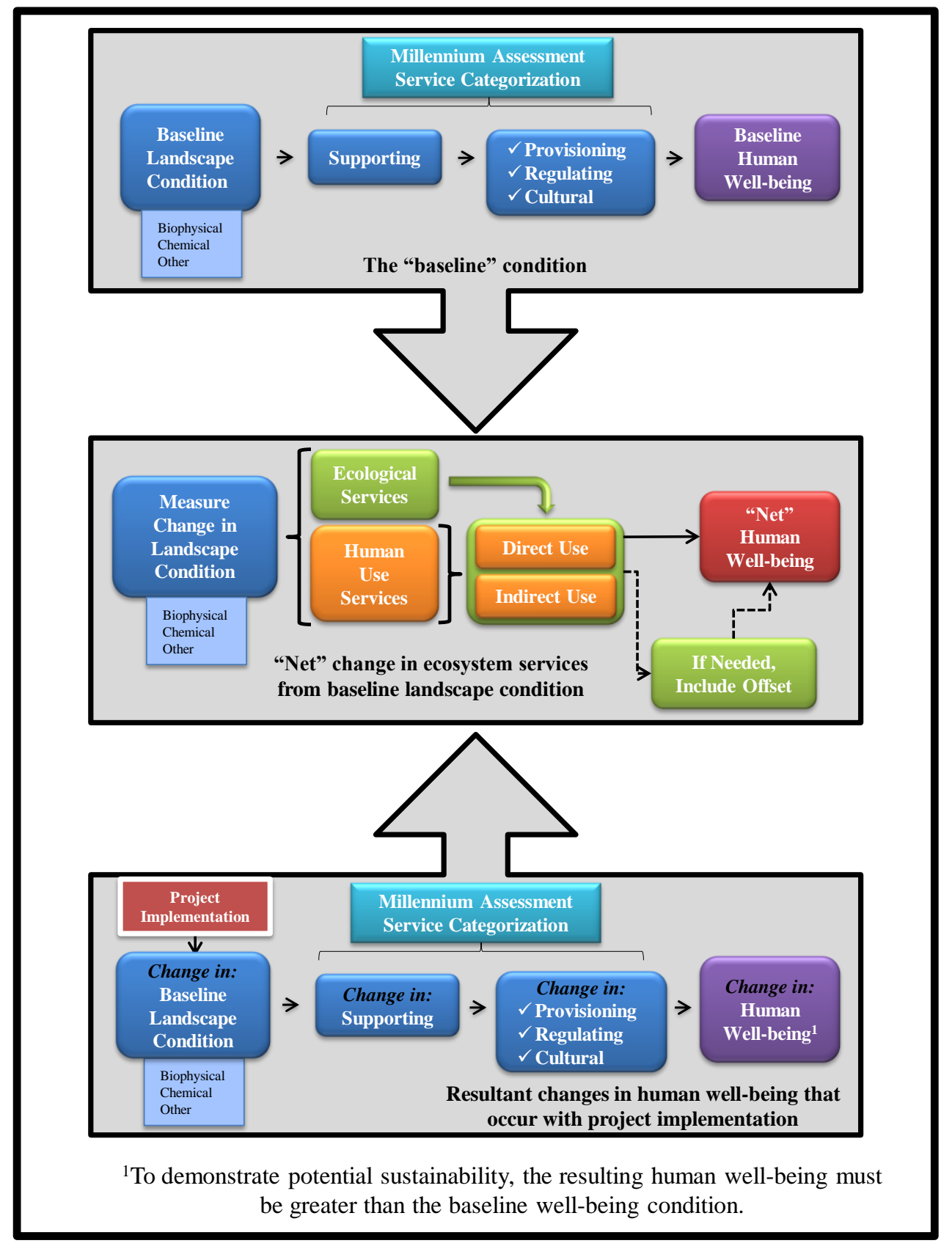

\subsubsection{Ecological Service Quantification}

As development continues, the public, through government policies, commonly makes trade-offs associated with actions affecting the environment. A good example is related to the 404 wetland permitting process in the United States. Under this process, project impacts to ecological services (e.g., wetlands) and associated human use services (e.g., water filtration) can be compensated for through the provision of wetland habitat to offset the impact (e.g., development impacts to wetland habitat). The policy provides a basis for making environmental tradeoffs. That is, impacts are allowed to occur provided the public is willing to accept the proposed compensation. This is consistent with dynamic efficiency and incorporates the notion that the benefits associated with the compensatory wetland 
restoration, acquisition, and/or enhancement are appropriately scaled to the level of habitat service loss so that the benefits are greater than or equal to the wetland losses. A method for comparing the ecological habitat service flows is provided in King and Adler [33]. This concept led to the development of the habitat equivalency analysis (HEA) method for determining appropriately scaled compensatory restoration [21,24,26-30].

Because many ecological habitat services are not traded in the marketplace, they do not have a direct monetary value. The HEA approach is a service-to-service equivalency approach that evaluates ecological habitat service losses and gains based on non-monetary metrics over time. It is important to recognize that ecosystem services are not static measurements but represent a flow of benefits over time as represented in Figures 3-6. Primary applications of HEA have been associated with balancing the negative ecological habitat impacts of an action with the positive ecological habitat benefits associated with a compensatory restoration action [29]. The balancing (i.e., equivalency) concept is based on the assumption that the public can be compensated for past and/or projected estimated losses in ecological habitat services through the provision of similar services of the same type in the future assuming the value the public places on losses and gains in ecological habitat services is the same [30].

This also assumes that indirect (passive and non-consumptive) values are incorporated within the ecological service value as well. While restrictive, an implication of this assumption is that it is not necessary to attempt to place a monetary value on the injured and restored ecological service flows, That is, despite the fact that HEA is an economic model, it uses ecological metrics to measure the flow of services. This provides an advantage over other methods of determining equivalent value because it can reduce the data and analysis requirements. The HEA methodology is flexible and can be adapted to individual sites and situations.

The HEA approach uses an environmental metric to measure changes to ecological habitat services and focuses on quantifying the area (e.g., hectares, acres) and level of impact over time in units typically represented as service-hectare-years (SHY's) or service-acre-years (SAY's). However, other metrics can be used and developed appropriate to the site and the key services being evaluated. HEA allows for service losses associated with an impact and service gains associated with restoration to be quantified in the same units so that offsetting mitigation, if needed, can be scaled equivalent to the adverse impact. The formal HEA methodology concurrently calculates both the level of impact and, given the characteristics of potential restoration, the appropriate level of restoration to compensate for those losses. However, the HEA methodology can be adapted to independently quantify either the relative impacts or benefits, independent from each other, associated with actions. This is the typical application within a NESA. For example, in comparing between various green practices, HEA might only be used to estimate relative project benefits. There may not be impacts to quantify. In other cases, a green practice may create potential service losses and gains concurrently. In others, the HEA may demonstrate an ecosystem service loss associated with an action. In order to illustrate the use of HEA to estimate ecological habitat service flows, one can apply, given the characteristics of either the impact or benefit of an action, the net change in ecological habitat service flows over time. By example, the HEA methodology could be used to calculate the areas of the various curves (shaded areas) presented in Figures 4-6 in units of SAY's, SHYs, or other alternative site specific metrics (e.g., services per linear distance of stream). An overview of the information, technical approach, and input parameters required to conduct habitat equivalency analysis is detailed in published articles and government 
sponsored reports $[21,26-30,34]$. Key information used for estimating ecological habitat service values includes an understanding of baseline conditions and the development of appropriate indicator metrics. Baseline conditions are important in that they serve as the point from which lost and gained services are compared. Reducing uncertainty regarding baseline service flows will provide a more accurate estimate of a projects flow of service benefits and potential service losses over time.

Ecological service losses and gains can be measured using a variety of indicator metrics and units. In many cases, the quantification of changes in ecological service flows is based upon selecting or developing an indicator (can be one or more metrics) that acts as a surrogate to represent the ecological service flows provided over time by the habitat and expressing the changes in services (for that indicator) under the different alternatives as a percentage change from a baseline or reference condition. Ecosystem studies, literature-based information, or a combination thereof, can be used to estimate how ecosystem services may change given an action. The metrics or indicators are selected based upon the site, habitats, and the scientific knowledge of those conducting the evaluation. The metric(s) are typically incorporated into a curve that represents the loss or gain of services over time.

For example, changes in one metric (e.g., fish density) may be selected as a surrogate to represent the loss or gain of ecological services provided by a riverine system. As presented in Figure 9, fish density was used to evaluate the service losses associated with an oil spill into a riverine system. Fish density data were collected in the river after the oil spill for two years to define the initial shape of the recovery curve. Subsequently, available literature data were used to support the development of the completed ecological recovery trajectory (Figure 9). In this example, fish density was evaluated in relation to the baseline condition and represented as a percent loss from the baseline condition. The estimated loss of ecosystem service value, given the 100 hectare impact area, was about 142 SHYs. In other cases, multiple metrics (e.g., invertebrate density, fish density, vegetation stem density) may be evaluated to represent the service flows from a habitat (Figure 10). When multiple metrics are used, their values can be weighted relative to one another to arrive at an overall service loss or gain curve. A conceptual example of a weighted curve is presented in Figure 11. In a manner to that presented in Figures 10 and 11, one or more indicator metrics can be selected to represent the gain in ecological service flows from an action that provides ecological benefits above the baseline condition. The ability to select indicator metrics on a case by case basis is important as it increases the flexibility of the approach for various sites and situations.

It should be noted that the inclusion of biodiversity metrics from which to evaluate ecosystem service flows and human well-being is a key consideration in evaluating green practices. Biodiversity is a term that expresses the variability and variety among the living world and can include consideration of species biodiversity, genetic diversity, and ecosystem diversity. Biodiversity provides ecosystem services directly and indirectly to human well-being. The protection of biodiversity is therefore important in the evaluation of a sustainable program. The NESA approach focuses on evaluating marginal changes in ecosystem services on a project specific basis. One of the most common measures of biodiversity that can be incorporated into the HEA methodology to support the estimation of ecological service flows is the species richness metric. This metric can serve as a key surrogate to represent ecological service flows and can be weighted higher, if desired, in relation to other metrics if multiple metrics are selected. As the scale of the project area becomes larger, for example on a large landscape basis such as a watershed, region or country, biodiversity metrics may 
serve as a primary indicator in developing the shapes of the curves presented in Figures 4-6. The level to which biodiversity metrics are included within the NESA approach would be a site specific and case by case consideration depending upon the project goals and the scale of the project.

Figure 9. Fish density as the indicator metric used to evaluate the ecological service losses associated with an oil spill into a riverine system.

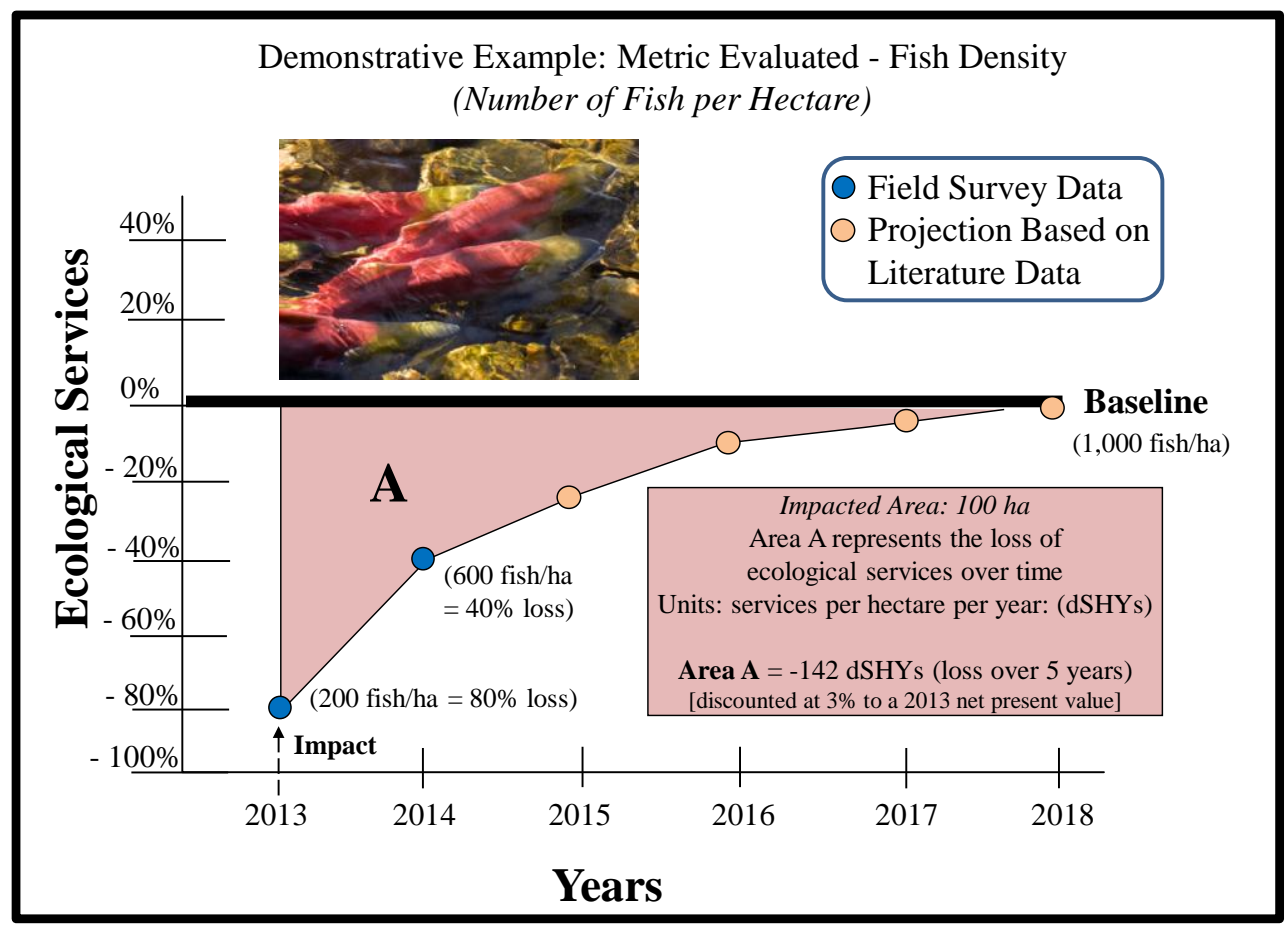

Figure 10. Use of multiple indicator metrics to represent the flow of ecological service losses associated with an oil spill into a riverine habitat.

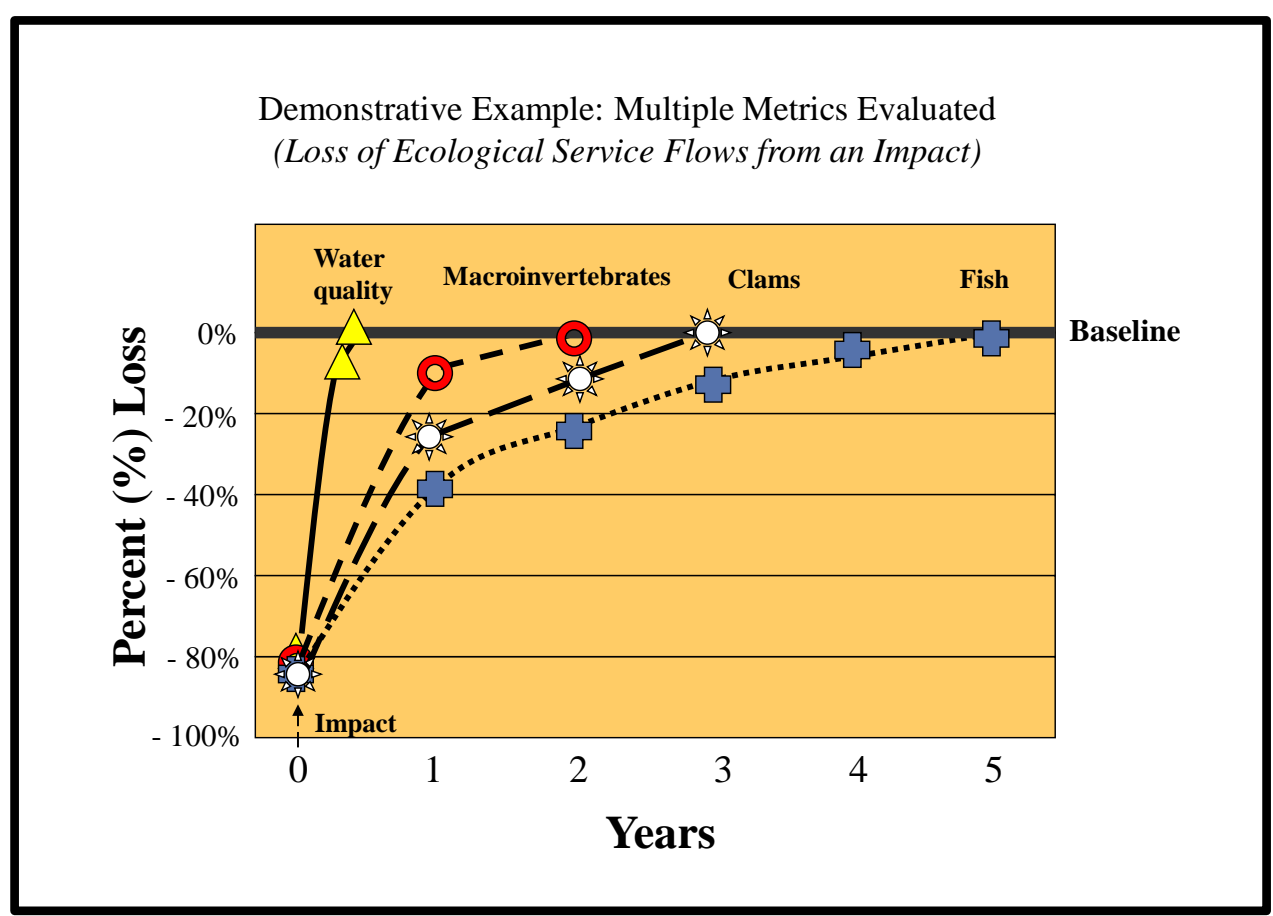


Figure 11. Weighted ecological service loss curve based upon the multiple indicator metrics presented in Figure 10.

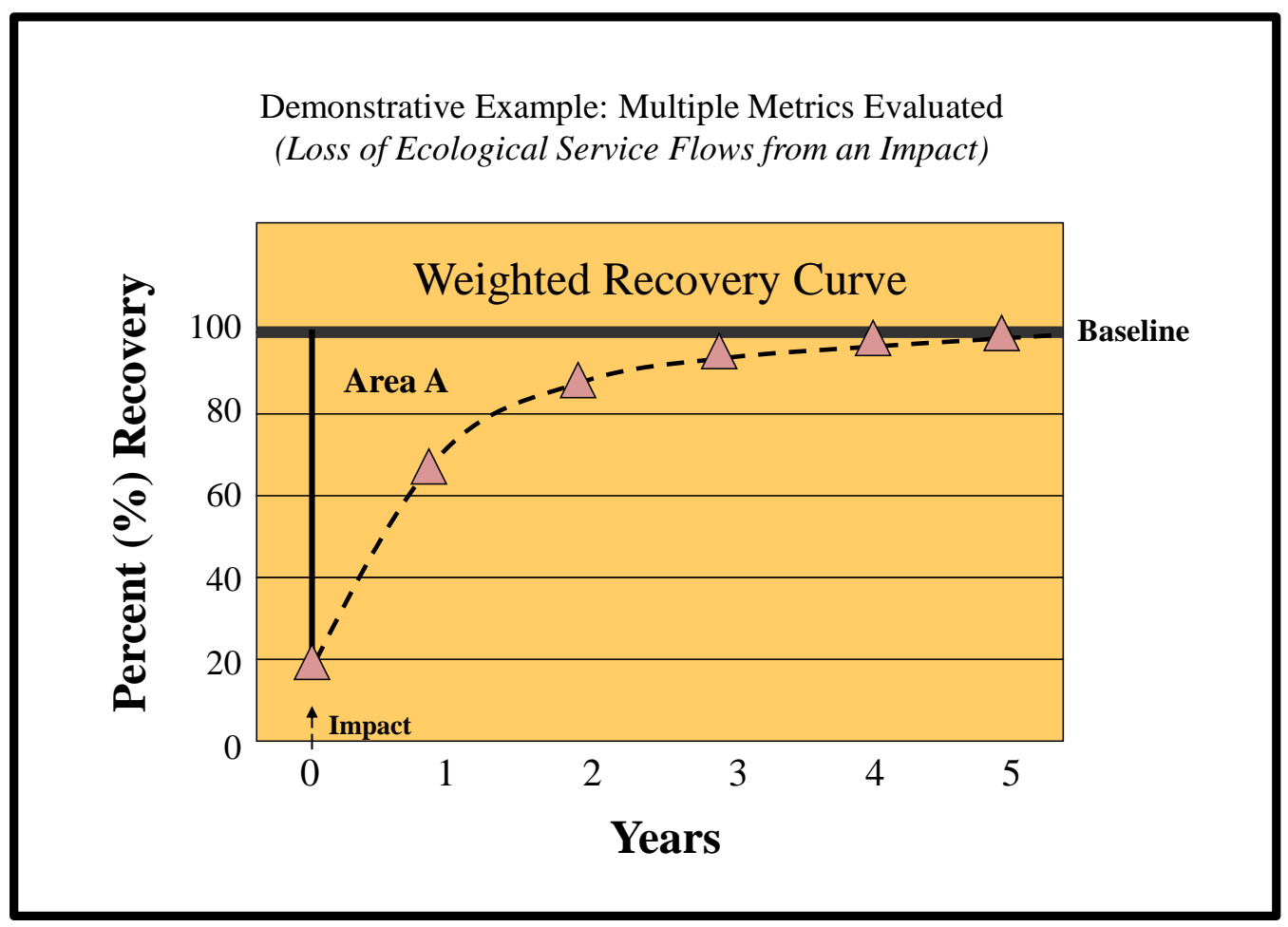

Aside from a base year, the calculations involve a discount rate that allows for the gains and losses to be evaluated from a net present value (NPV) standpoint. Within the HEA methodology, calculations of ecological service losses and gains associated with a project are computed over time. A discount rate can be applied to the HEA units (e.g., SHY, SAY) since they represent time accumulated service flows $[21,26-30,33,34]$. In these cases, the units are typically displayed as a dSHY or a dSAY which represent ecological habitat values. The discount rate is the rate at which the public is indifferent to consuming goods now or sometime in the future. In evaluating ecological habitat service flows, applications of the HEA methodology must account for the absolute difference in the flow of services from the ecological resources resulting from green practices and how those services are distributed over time. In addition, for any given green practice, it is likely that the ecological habitat service loss or gain may not always be constant over time (Figures 4-6). An assessment of the shape of the various ecological habitat service flow curves over time is necessary. Quantifying the ecological service value of a green practice can be conducted prior to project implementation through the use of projected metrics based on scientific data and professional judgment. This approach would allow green practice alternatives to be compared in a manner similar to how compensatory restoration project alternatives are compared within the NRDA process.

Within a NESA, HEA is a key method used to quantify changes in ecological habitat service flows. HEA has been upheld in U.S. federal court as an appropriate method to evaluate habitat service losses and habitat service gains associated with restoration [35,36]. Parameter assumptions can be made in a relatively short time frame to develop the shapes of potential ecological habitat service benefit or service loss curves. In other cases, detailed longer-term studies can be employed to generate data to support the development of the curves. The HEA methodology has been used to provide a practical 
and flexible approach to generate sufficient information to support decision-making. Curve development should focus on reducing uncertainty to an acceptable level. In cases where uncertainty exists, conservative assumptions can be incorporated into the development of the curves. Aside from the quantification of ecological habitat services using HEA, there are other methods to quantify changes in direct human use services (Figure 7) associated with green practices and actions affecting the environment. These are discussed in the following section.

\subsubsection{Human Use Service Quantification Methods}

Ecosystems generate several different types of benefits for humans including benefits that are enjoyed directly through consumption, indirectly through their support and production of directly enjoyed goods and services, and through non-consumptive means such as intrinsic and existence values. Together, the total sum of the different types of benefits generated is the total economic value of ecosystem services. There are several economic models that are capable of estimating different components of total economic value. Models that are specifically capable of estimating values of public goods and services include hedonic pricing, stated preference methods, and the travel cost model [37]. Each method measures a different type of public value. For example, non-consumptive values can be estimated using stated preference methods whereas direct-use values can be estimated using the travel cost method.

Hedonic models use observed price differentials in housing markets to assess the marginal implicit price that local environmental attributes add to housing prices [37]. Housing prices are a function of housing characteristics, neighborhood qualities, and environmental aspects. When the various determinants of housing prices are controlled for such as number of bedrooms and size, such purchases reveal the values people hold for environmental goods [38]. Hedonic pricing models are commonly used to assess the impact of pollution and proximity to open spaces [38,39].

Stated preference methods are capable of measuring values that are not observed by the choices people make [37]. These methods use survey instruments and hypothetical situations to assess non-use values such as preservation and conservation, bequest values, and intrinsic value of open space and species. Survey instruments are designed to walk respondents through a situation in which the quality or quantity of an ecosystem service will change. The goal of the exercise is to obtain information on individual's "willingness-to-pay" for the environmental amenity where "willingness-to-pay" is defined as the maximum sum of money the individual would be willing to pay rather than do without an increase in the ecosystem service [37].

The travel cost method is able to measure the direct use of nature, whereas, hedonic pricing and stated preference methods measure indirect and non-consumptive values. The value derived from the direct use of nature is observed through the choices people make regarding the use of natural resources. The travel cost model measures the direct use value of nature by examining how much individuals expend (i.e., time and money) to experience the natural environment in a variety of recreational, educational, and cultural ways. The value of these services is estimated by assessing the net gain to society that is derived from the resource base [37]. This net economic value, known as the consumer surplus, is the additional value an individual holds for recreational use of nature above the cost required to enjoy the outdoor experience [37]. When the resource quality or quantity changes, the 
additional value above expenditures will increase or decrease. Therefore, changes in the availability, access, or quality of the recreational experience can be estimated by examining the difference in the baseline value and the resulting consumer surplus associated with the project or management plan.

Conducting primary economic studies may often be infeasible given the cost and time required to collect and analyze the data. Therefore, many analysts estimate publically valued ecosystem services using benefit transfer methods. Benefit transfer refers to methodologies that use knowledge gained from past studies regarding the value of similar services at comparable locations and employs this knowledge at a new location. There are several ways to transfer values including unit-value or mean value transfer, a benefit function transfer, and a meta-analytic transfer [40]. Transferred values are adjusted for population, income, and other factors in order to obtain an estimate of the value at the project location [41].

Valuation of the direct use of nature using benefit transfer methods requires quantification of recreational trips and the net change in value resulting from the project. Quantification of trip equivalents should include all the different activities available, the number of users for the different activities, and other information such as variability and seasonal use. Estimation should be adjusted for any anticipation in the change in the number of trips taken per season due to project implementation. Monetization of direct use can be estimated by transferring per trip consumer surplus values estimated at other locations for each activity. Once direct human use services have been quantified and monetized, the flow of service value is projected through time. The stream of value can be discounted and presented in net present value terms. If the stream of value is positive, this indicates the net change in service level is above baseline. A conceptual example that demonstrates the gain in human use recreational value associated with the enhancement of a green space is depicted in Figure 12. The enhancement could entail improvements to habitat quality and/or improved access to the habitat.

\subsubsection{Uncertainty}

The ecological and human use quantification approaches, as with all approaches, include a level of uncertainty. For example, as seen in the curves presented in Figures 4-6, quantifying ecosystem service values requires estimating projected changes to service flows over time. The uncertainty can be handled as various stages of the quantification process. In some cases, given the range of uncertainty, quantification can bound the range of value based on low and high range estimates. Experience has shown that in many cases, this level of detail is sufficient to evaluate a project or demonstrate the relative difference between two or more competing actions. In other cases, probabilistic distributions with Monte Carlo methods can be used [41]. In the case where further refinement of uncertainty is necessary, additional data collection activities can be undertaken to evaluate service flow changes over time. In this manner, the level of effort to make a decision can be managed.

In addition, uncertainty can be managed through the development of follow-on monitoring to establish that the projected benefits of an action (i.e., the projected flow of ecosystem services into the future) are being realized as they were initially projected. This would allow for adaptive management to be incorporated into project implementation. 
Figure 12. Gain in human use recreational value associated with the enhancement of a green space.

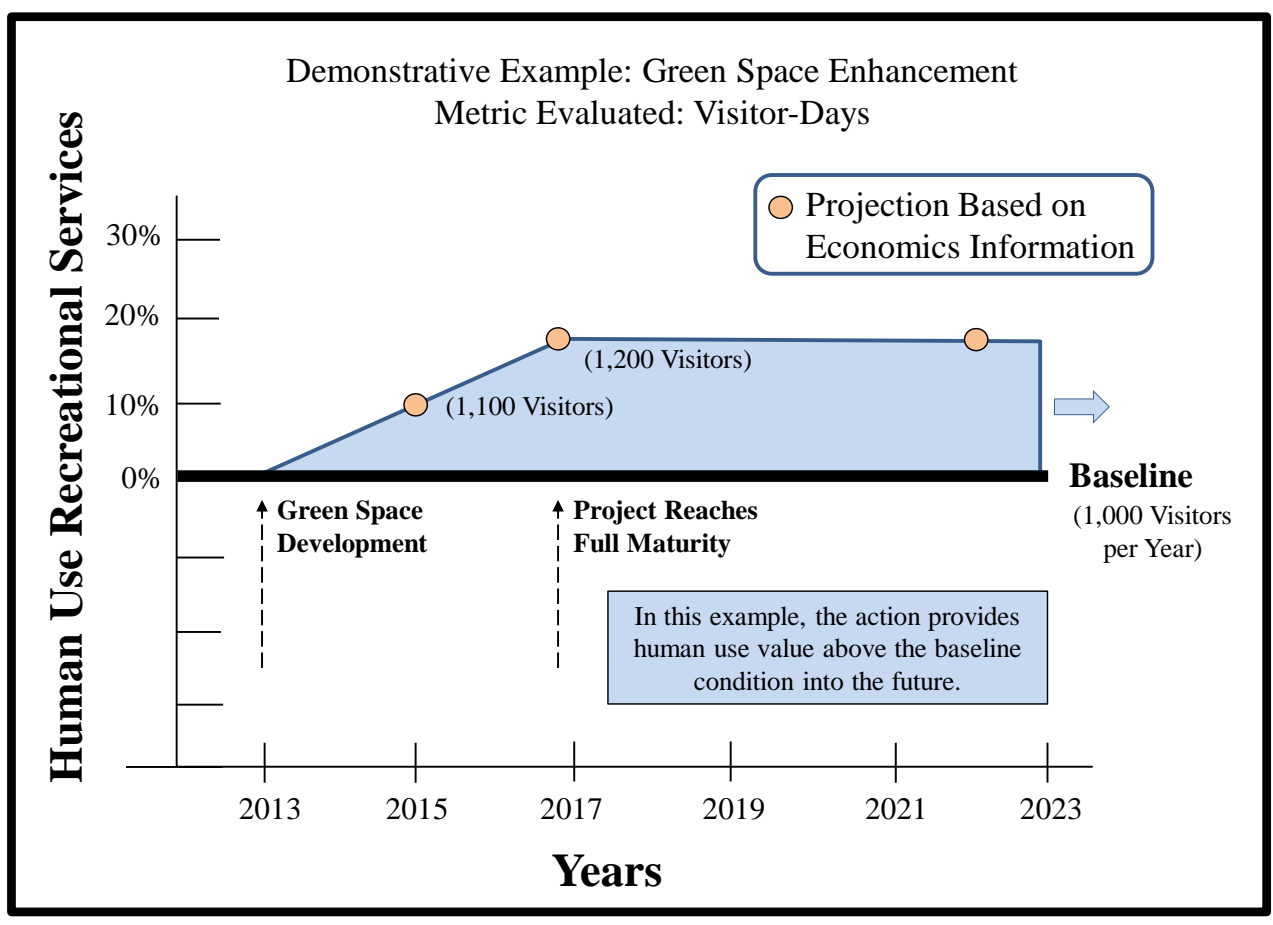

\section{Outcomes of a Net Ecosystem Service Analysis}

The overall purpose of conducting a NESA is to provide information to decision-makers, using quantifiable metrics, as to whether or not an action (e.g., green practice) provides a potentially sustainable outcome at a meaningful scale, and to demonstrate environmental stewardship. The outcome of a NESA is dependent upon the type and scale of the action and the site characteristics. This approach is similar to the manner in which the value of restoration alternatives are evaluated and compared in regard to their provision of natural resource services within the NRDA process. In evaluating the effects that an action can have on the environment, the approach presented herein uses an ecological service quantification methodology (i.e., HEA) and/or one or more human use service quantification methods (e.g., travel cost, benefits transfer, etc.) depending upon the specific action and site characteristics. These methods are used to calculate the net change in ecological and/or human use service value over time (e.g., benefits, human well-being). Ecological service values are quantified using an environmental metric such as dSAY or dSHY while human use services are quantified in terms of user-days, visitor-days, monetary terms, or a combination of similar metrics.

\subsection{Output Example}

As an example, four alternative projects or management plans that a business could choose from are presented as Alternatives A through D in Figure 13. The four projects include: (1) Alternative A which produces a large net gain in ecosystem services but relatively low financial gains, (2) Alternative B which produces relatively less gains in ecosystem services compared with Alternative A but larger financial gains, (3) Alternative $\mathrm{C}$ which results in a net loss of ecosystem services but generates the largest financial gains, and (4) Alternative D (the same as Alternative C but includes an offset project 
which generates ecosystem services). Alternative D (including the offset), results in slightly lower financial gains than Alternative $\mathrm{C}$ (with no offset) due to the additional expenditures required to gain ecosystem service benefits.

Figure 13. Summary of alternative outcomes using ecological and human use service metrics.

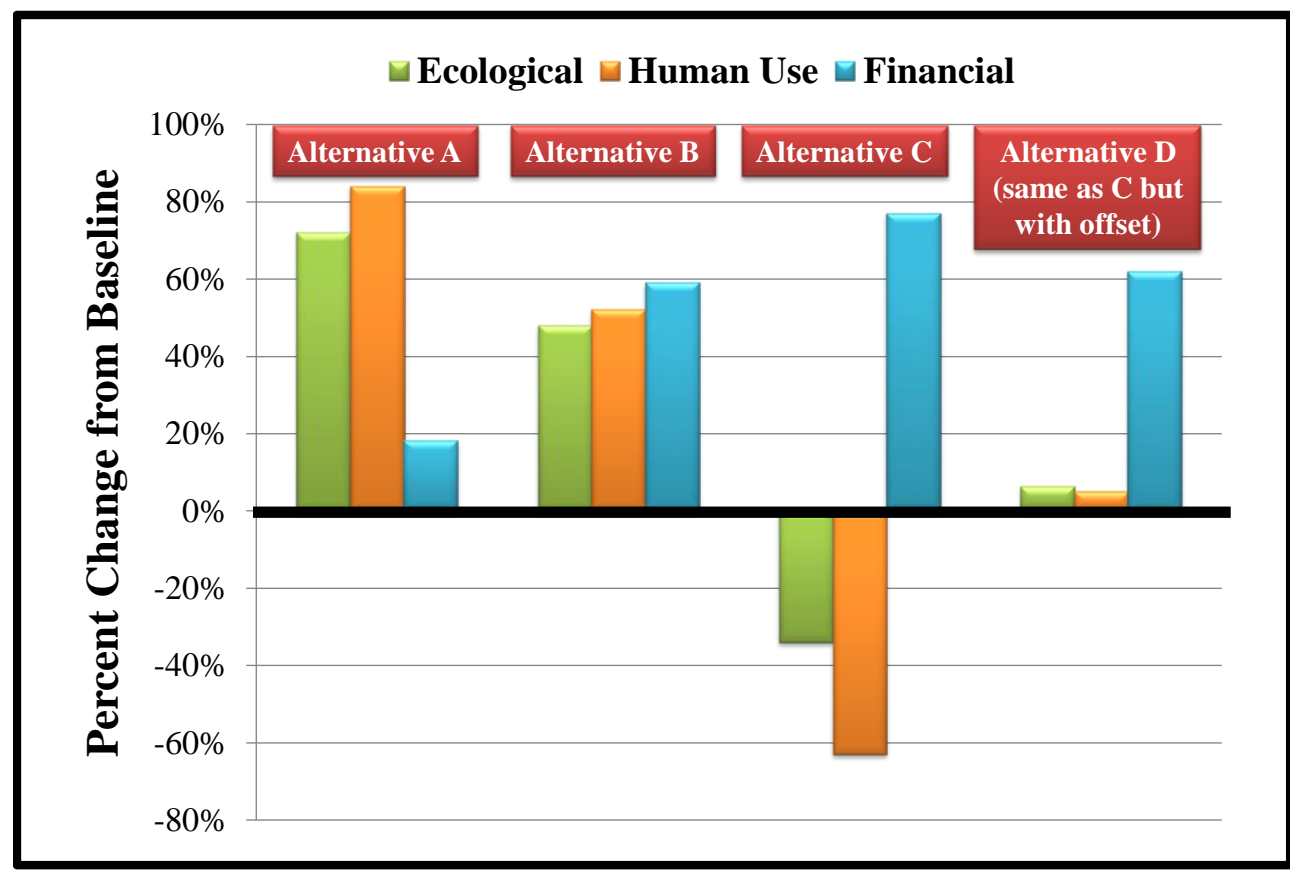

If a business were to only consider the financial gains resulting from a project, the business would choose Alternative C. That project alternative would not be considered potentially sustainable. However, in order to choose a project that is sustainable, the business's choice set would be contingent upon the project resulting in no net loss of ecosystem services (human well-being). Therefore, the business's choice set would be constrained to Alternative A, Alternative B, and Alternative D (including an offset). The creation of ecosystem service value above and beyond the sustainable baseline level will lead to informed conclusions as to whether or not the action embodies environmental stewardship.

\subsection{Case Study Outcome Examples}

The NESA approach, incorporating the ecological and human use service valuation methods referenced above, has been used to support decision-making for multiple environmental issues such as environmental impact analysis, restoration alternative comparisons (e.g., NRDA), United States 404 wetland permitting mitigation analysis, remedial alternative comparisons, pesticide evaluations, and land reuse and development designs (e.g., brownfield sites, property transfers, and asset value estimation).

As an example, the summary output from a NESA analysis to support a final environmental impact statement (FEIS) related to the evaluation of land management decisions is provided as Exhibit 1 . The work was conducted for the Tennessee Valley Authority (TVA) in the United States and is referenced within the FEIS. Exhibit 1 is reproduced from the final report that provided supporting information for 
the FEIS. TVA is responsible for the management of 293,000 acres of public land and 11,000 miles of public shoreline in the TVA region. In this case, the NESA analysis supported the balancing of the risks, benefits and tradeoffs associated with competing development alternatives to support stakeholder decision-making. The NESA evaluated how ecological services, human use recreational services, and real estate values would change given the various alternatives presented in the FEIS. In this example, the key service metrics were identified by the stakeholders for evaluation. In a similar manner as could be applied to sustainability, stakeholders could select key service indicators as a surrogate to represent the overall sustainability of specific alternatives.

Exhibit 1. Summary of alternative outcomes developed in support of a Tennessee Valley Authority final environmental impact statement assessing land development alternatives.

The percent differences of each alternative relative to Alternative A are graphically presented in Exhibit ES-4.

\section{EXHIBIT ES-4}

Ecological, Recreational, and Real Estate Values per Acre per Alternative (Using Alternative A as a Baseline)

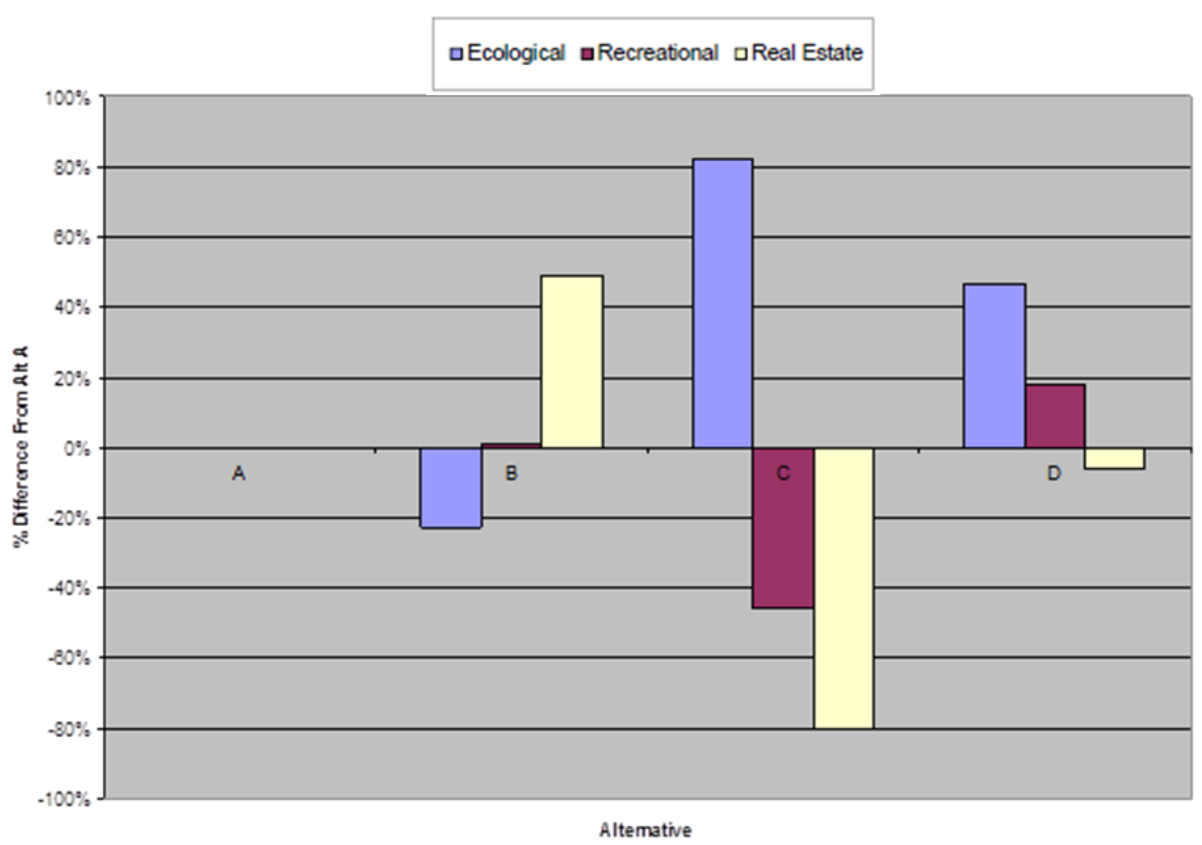

Alternative D is intended to define how specific land use proposals and available parcels likely fit into the regions demographic and real estate trends and the physical attributes of the parcels. Implementing Alternative D will produce an optimum blend of conservation, human use recreation, and economic development (Exhibits ES-2 and ES$4)$.

Alternative $\mathrm{D}$ is the only alternative providing positive increases in both ecological and human use recreation value compared to Alternative A. Alternative B results in a loss of ecological value, while Alternative $C$ results in a loss of both recreational and real estate value compared to Alternative A.

Alternative D requires implementing the following changes for six parcels:

- $\quad$ Rezoning certain parcels

- Subdividing parcels into areas according to their suitability for ecological, recreational, or real estate purposes

- $\quad$ Reconfiguring parcels to group together areas of like purpose 
In a second example, a NESA analysis was conducted for a confidential party to compare between competing remedial alternative designs. The project was located in the northern alpine region of Italy in Pallanza Bay. In this case, the NESA evaluated how ecological and human use services changed between several alternative remedial actions in relation to site risks and remedial costs. The summary output for this project is presented in Figure 14 as reproduced from Colombo et al. [17].

Figure 14. Case study summary output related to remedial decision-making. In the Figure, MNR is monitored natural recovery while RHE is riverine habitat enhancement-reproduced from Colombo et al. [17].

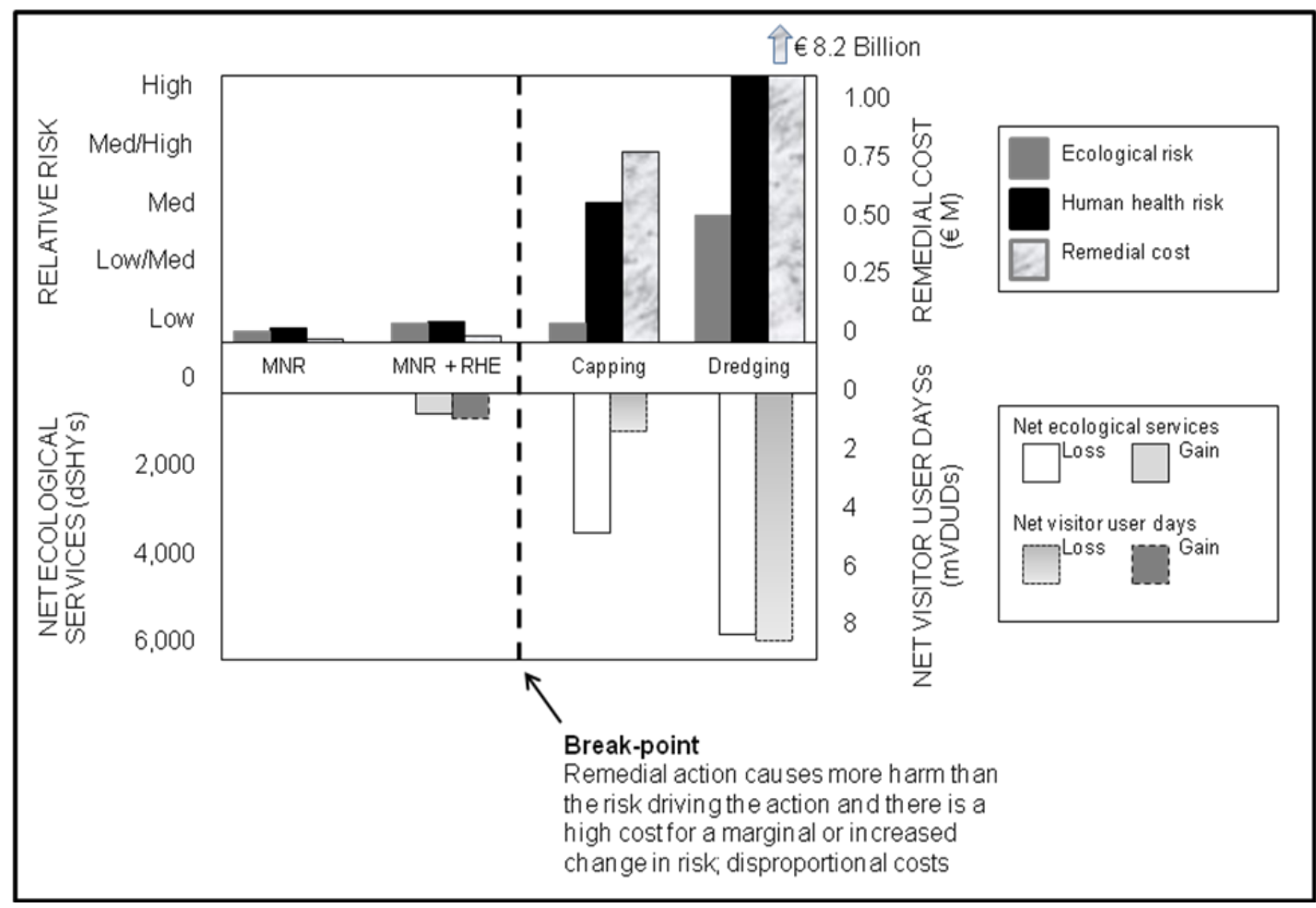

The summary output from the two case studies provides examples as to how a practical approach using the ecological and human use service quantification methods described in Section 3.1.1 has been incorporated into analyses to support decision-making. In addition, in balancing the risks, benefits and tradeoffs associated with the alternatives in the above referenced case studies, the provision of ecosystem service values above baseline levels (e.g., the net environmental benefit) could be used to support statements regarding the environmental sustainability and stewardship of the proposed actions.

\subsection{Addressing Environmental Stewardship}

In addition to demonstrating potential environmental sustainability, the practical approach presented herein would also serve as a quantitative method to demonstrate environmental stewardship. Environmental stewardship draws on the ethical responsibility of undertaking the management of natural stocks of capital and assets. Stewardship introduces important wider obligations to the public, to future generations, and to other species of the natural world [42]. This wider responsibility means that stewardship is more inclusive than traditional management aimed at optimizing private interests. 
The importance of the ethical aspects of stewardship is that they provide an explicit, rational, moral underpinning for our treatment of natural resources and the natural world [42].

Given this understanding of environmental stewardship, the NESA approach could be used to demonstrate not only the potential for environmental sustainability, but also environmental stewardship. As shown in Figure 13, Alternatives A and B produce significant levels of ecosystem services (ecological and human use) above and beyond the sustainable level (baseline condition). If a green practice creates net ecological service and human use service value above the baseline condition, it would be considered to embody the concept of environmental stewardship. The level of stewardship would be dependent upon the level to which ecosystem services are provided above and beyond the baseline level.

\subsection{Considerations in the Use of the NESA Approach}

The NESA approach provides a framework from which decisions can be made related to the potential environmental sustainability of various actions. The approach presented herein incorporates environmental and human use economic methodologies that are scientifically-based and litigation-tested. However, the potential application of the approach and associated methodologies is dependent upon the site and specific green practice being addressed. For example, it is necessary to be able to select and quantify one or more key metrics to represent service flows over time. This approach makes the assumption that the selected metric(s) appropriately reflect the overall flow of ecosystem services over time when in fact, the mix of ecosystem services can be complex and may not be able to be reflected through the selection of one or more metrics.

Another consideration in the use of the NESA approach is the appropriateness of incorporating an environmental offset. Offsets should not be incorporated into projects that may adversely affect ecosystem assets potentially nearing their environmental limits. In addition, the NESA approach is most appropriately implemented when evaluating marginal changes in ecosystem services on a specific project basis. This usually entails well defined project areas and impacts. As the scale of the analysis becomes larger, for example on a large landscape basis such as a region or country, the resolution of the analysis becomes less refined.

Lastly, the NESA approach is enhanced by stakeholder involvement to transparently demonstrate potential environmental sustainability and stewardship.

\section{Summary and Conclusions}

A practical approach for demonstrating the sustainability of actions (e.g., green business practices) that affect the environment is critical in determining the extent to which the action provides a sustainable outcome at a meaningful scale, and in demonstrating environmental stewardship. The NESA approach incorporates established ecological and human use quantification methods to evaluate changes in ecosystem service flows that arise from implementation of project actions. To demonstrate potential sustainability, the approach must also consider the need to satisfy intergenerational equity objectives. Key tenets of the approach presented herein include the following: 
- The overarching premise of the approach is that human well-being is directly related to changes in ecosystems and associated services;

- It is not necessary, when comparing between alternative actions, to quantify the overall ecosystem service "stock" value of a resource;

- What matters is the "net" change in human well-being that is associated with an action;

- The net change in ecosystem services can be represented using one or a combination of metrics, monetary and/or non-monetary;

- If a net positive change in ecosystem services relative to the baseline condition occurs for an action, that action could be considered potentially sustainable; and

- If a green practice creates net ecosystem service value above the baseline condition, it would be considered to embody the concept of environmental stewardship with the level of stewardship dependent upon the level to which ecosystem services are provided above and beyond the baseline level.

The use of a practical approach from which private business and government representatives can make decisions regarding environmental sustainability and stewardship has the potential to provide for:

- A decision-making approach that utilizes formally quantified metrics;

- Cost effective, science-based, technically defensible, transparent, and flexible methods;

- An approach to track and document the net benefit of actions so that value can be recognized;

- Integration of risk mitigation within project design potentially expanding project design alternatives;

- Forward thinking and incorporation of project benefits within the early stages of project development;

- Collaboration amongst stakeholders;

- A better understanding of project risks and benefits;

- Expedited decision-making which will allow ecosystem service benefits to be recognized sooner; and

- An increased ability to ensure the success of green project actions to meet human well-being goals through the incorporation of adaptive management approaches.

\section{Conflict of Interest}

The authors declare no conflict of interest.

\section{References and Notes}

1. World Commission on Environment and Development. Our Common Future, Chapter 1: A Threatened Future. Available online: http://www.un-documents.net/ocf-01.htm/ (accessed on 10 February 2013).

2. World Commission on Environment and Development. Our Common Future, Chapter 2: Towards Sustainable Development. Available online: http://www.un-documents.net/ocf-02.htm/ (accessed on 10 February 2013).

3. United Nations General Assembly. 2005 World Summit Outcome, Resolution A/60/1, adopted by the General Assembly on 15 September 2005. Available online: http://unpan1.un.org/intradoc/ groups/public/documents/un/unpan021752.pdf (accessed on 26 February 2013). 
4. Arrow, K.; Dasgupta, P.; Goulder, L.; Daily, G.; Ehrlich, P.; Heal, G.; Levin, S.; Mäler, K.G.; Schneider, S.; Sterrett, D.; et al. Are We Consuming Too Much? J. Econ. Perspect. 2004, 3, 147-172.

5. Stavins, R.N.; Wagner, A.F.; Wagner, G. Interpreting sustainability in economic terms: dynamic efficiency plus intergenerational equity. Econ. Lett. 2003, 79, 339-343.

6. It should be recognized that some people view intragenerational equity (i.e., the treatment of different groups within the same generation) to be as important as intergenerational equity [7].

7. Stiglitz, J.E.; Sen, A.; Fitoussi, J.-P. Report by the Commission on the Measurement of Economic Performance and Social Progress. Available online: http://www.stiglitz-sen-fitoussi.fr/documents/ rapport_anglais.pdf (accessed on 22 April 2013).

8. Kaldor, N. Welfare Propositions in Economics and Interpersonal Comparisons of Utility. Econ. J. 1939, 49, 549-552.

9. Hicks, J. The Foundations of Welfare Economics. Econ. J. 1939, 49, 696-712.

10. European Commission. Guide to Cost-Benefit Analysis of Investment Projects; Directorate General Regional Policy, European Commission: Brussels, Belgium 2008. Available online: http://ec.europa.eu/regional_policy/sources/docgener/guides/cost/guide2008_en.pdf (accessed on 27 February 2013).

11. Economic Evaluation Branch. Guide to Benefit-Cost Analysis in Transport Canada; Transport Canada: Ottawa, Canada, 1994.

12. Weisbrod, B.A. Benefit-Cost Analysis of a Controlled Experiment: Treating the Mentally Ill. J. Hum. Resour. 1981, 16. 523-548.

13. Plotnick, R.D. Applying Benefit-Cost Analysis to Substance Abuse Prevention Programs. Int. J. Addict. 1994, 29, 339-359.

14. Weisbrod, B.A.; Hansen, W.L. Benefits, Costs, and Finance of Public Higher Education, Markham Publishing; Markham Pub Co.: Chicago, IL, USA, 1969.

15. Moll, K.D.; Baum, S.; Capener, E. Hazardous Wastes: A Risk-Benefit Framework Applied to Cadmium and Asbestos; Stanford Research Institute: Menlo Park, CA, USA, 1975.

16. Millennium Ecosystem Assessment. Ecosystems and Human Well-being: Full Report; Island Press: Washington, DC, USA, 2005.

17. Colombo, F.; Nicolette, J.; Wenning, R.; Travers, M. Incorporating Ecosystem Service Valuation in the Assessment of Risk and Remedy Implementation. Chem. Eng. Trans. 2012, 28, 55-60.

18. Nicolette, J.; Rockel, M.; Pelletier, D. Incorporating Ecosystem Service Valuation into Remedial Decision-Making: Net Ecosystem Service Analysis. Superfund and NRD Lit. Com. News. 2011, 7, 9-13.

19. Efroymson, R.; Nicolette, J.; Suter, G. A Framework for net environmental benefit analysis for remediation or restoration of contaminated sites. Environ. Manage. 2004, 34, 315-331.

20. Efroymson, R.; Nicolette, J.; Suter, G. A Framework for Net Environmental Benefit Analysis for Remediation or Restoration of Petroleum-Contaminated Sites; ORNL/TM-2003/17; Oak Ridge National Laboratory: Oak Ridge, TN, USA, 2003.

21. REMEDE. Deliverable No. 6A: Review Report on Resource Equivalence Methods and Applications. Available online: http://www.envliability.eu/docs/REReviewUS_D6A_Stratus_ FINAL.pdf (accessed on 27 February 2013). 
22. Ecological Services - The physical, chemical, or biological functions that one natural resource provides for another natural resource and thus indirectly provides value to the public (e.g., the provision of food for wildlife, protection from predation, and nesting habitat, among others) [24].

23. Human use services - the human uses of natural resources or functions of natural resources that provide direct value to the public (e.g., fishing, hunting, bird-watching, boating, nature photography, and education, among others) [24].

24. NOAA. Oil Pollution Act Regulations; 15CFR Part 990; National Oceanic and Atmospheric Administration: Washington, DC 1996; p. 19.

25. Boyd, J.; Krupnick, A. The Definition and Choice of Environmental Commodities for Nonmarket Valuation; Resources for the Future: Washington, DC, USA, 2009.

26. NOAA. Habitat equivalency: An overview. National Oceanic and Atmospheric Administration, Damage Assessment and Restoration Program; National Oceanic and Atmospheric Administration: Silver Spring, MD, USA, 1995.

27. Dunford, R.; Ginn, T.; Desvousges, W. The use of habitat equivalency analysis in natural Resource damage assessments. Ecol. Econ. 2003, 48, 49-70.

28. Chapman, D.; Iadanza, N.; Penn, T. Calculating Resource Compensation: An Application of the Service-to-Service Approach to the Blackbird Mine Hazardous Waste Site; Technical Paper 97-1; National Oceanic and Atmospheric Administration Damage Assessment and Restoration program: Washington, DC, USA, 1998.

29. Nicolette, J.P.; Rockel, M.; Kealy, M.J. Quantifying ecological changes helps determine the best mitigation Gulf Publishing Company. Pipeline Gas Ind. 2001, 52-57.

30. NOAA. Scaling Compensatory Restoration Actions: Guidance Document for Natural Resource Damage Assessment under the Oil Pollution Act of 1990; NOAA Damage Assessment and Restoration Program: Washington, DC, USA, 2007. Available Online: http://www.darrp.noaa.gov/ library/pdf/scaling.pdf (accessed on 8 August 2012).

31. English, E.P.; Peterson, C.H.; Voss, C.M. Manuscript of Ecology and Economic of Compensatory Restoration: Final Report; Costal Response Research Center, Center for Spills in the Environment, University of New Hampshire: Durham, NH, USA, 2009.

32. Bateman, I.J.; Mace, G.M.; Fezzi, C.; Atkinson, G.; Turner, K. Economic Analysis for Ecosystem Service Assessment. Environ. Resour. Econ. 2011, 48, 177-218.

33. King, D.M.; Adler, K.J. Scientifically Defensible Compensation Ratios for Wetland Mitigation; United States Environmental Protection Agency, Office of Policy, Planning and Evaluation: Washington, DC, USA, 1991.

34. Fonseca, M.S.; Julius, B.E.; Kenworthy, W.J. Integrating biology and economics in seagrass restoration: How much is enough and why? Ecol. Eng. 2000, 15, 227-237.

35. United States 1997. United States v. Melvin Fisher. United States District Court for the Southern District of Florida, Key West Division Case Numbers 92-10027-CIV-DAVIS, and 95-10051CIV-DAVIS. Decided 30 July 1997, Filed 30 July 1997. 977 F. Supp. 1193; 1997 U.S. Dist. LEXIS 16767.

36. United States 2001. United States of America and Internal Improvement Trust Fund v. Great Lakes Dredge and Dock Company. United States District Court for the Southern District of Florida D. C. Docket No. 97-02510-CV-EBD. 
37. Freeman, A.M. The Measurement of Environmental and Resource Values: Theory and Methods, 2nd ed.; Resources for the Future: Washington, DC, USA, 2003.

38. Smith, V.K.; Huang, J.C. Can Markets Value Air Quality? A Meta-Analysis of Hedonic Property Value Models. J. Polit. Econ. 1995, 103, 209-227.

39. McConnell, V.; Wells, M. The Value of Open Space: Evidence from Studies of Nonmarket Benefits; Resources for the Future: Washington, DC, USA, 2005.

40. Rosenberger, R.S.; Loomis, J.B. Benefits Transfer of Outdoor Recreation Use Values; Rocky Mountain Research Station, U.S.D.A. Forest Service: Fort Collins, CO, USA, 2001.

41. McCay, D.F.; Rowe, J.J.; Whittier, N.; Sankaranarayanan, S.; Etkin, D.S. Estimation of potential impacts and natural resource damages of oil. J. Hazard. Mater. 2004, 107, 11-25.

42. Worrell, R.; Appleby, M.C. Stewardship of Natural Resources: Definition, Ethical and Practical Aspects. J. Agric. Environ. Ethics 2000, 12, 263-277.

(C) 2013 by the authors; licensee MDPI, Basel, Switzerland. This article is an open access article distributed under the terms and conditions of the Creative Commons Attribution license (http://creativecommons.org/licenses/by/3.0/). 